\title{
Intelligent Data Analysis of Interactions and Relationships among Technological Pedagogical Content Knowledge Constructs via Rough Set Analysis
}

\author{
Kemal Özgen \\ Dicle University, Ziya Gökalp Education Faculty, Mathematics Education, Turkey \\ ORCID: 0000-0002-7015-6452 \\ Serkan Narlı \\ Dokuz Eylül University, Buca Education Faculty, Mathematics Education, Turkey \\ ORCID: 0000-0001-8629-8722
}

\begin{abstract}
This study focuses on the relationship among Content Knowledge (CK), Pedagogic Knowledge (PK), and Technological Knowledge (TK) using Technological Pedagogical Content Knowledge (TPACK). The aim of the study is to use the determined relationship to provide mathematical clarity using the Rough Set Theory, which is commonly used in areas such as Artificial Intelligence, Data Reduction, Determination of Dependencies, Estimation of Data Importance and the establishment of Decision (control) Algorithms. Accordingly, TPACK scale was applied to 340 preservice teachers who, at the time of conducting this study, were continuing their teaching at elementary (grade 5-8) and secondary (grade 9-12) Mathematics Teaching Department. The gathered data was broken into three different groups - low, medium and high. The data grouping allowed for applying of the Rough Set Analysis. This will enable TPACK constructs to assign prospective teachers to any of the three identified groups. Analysis has put forth that the CK, PK and TK components explain TPACK with a dependency degree of 0.105 and that even though the levels of significance of each component is low by itself, it cannot be removed from the data set. Lastly, decision rules have been established between CK, PK and TK with TPACK.
\end{abstract}

Keywords: content knowledge, pedagogical knowledge, rough sets, technological knowledge, technological pedagogical content knowledge

\section{INTRODUCTION}

The Pedagogical Content Knowledge (PCK) put forth by Shulman (1986) in teacher education has recently become popular again and different approaches and models (Mishra \& Koehler, 2006) have been tried to be developed using this model. The Technological Pedagogical Content Knowledge (TPACK) is currently viewed as the most widely accepted framework to account for the knowledge teachers need to integrate educational technology (Sang, Tondeur, Chai \& Dong, 2016, p. 49). According to Brantley-Dias and Ertmer (2013), the TPACK framework has become a popular structure for examining the types of teacher knowledge need to ensure technology integration.

In addition to the intense interest in the TPACK model, several theoretical (Abbitt, 2011; Chai, Koh \& Tsai, 2013; Cox \& Graham, 2009; Voogt, Fisser, Pareja Roblin, Tondeur, \& van Braak, 2013) 
and practical (Archambault \& Barnett, 2010; Brantley-Dias \& Ertmer, 2013; Sang et al., 2016) studies reported about limitations, contradictions and difficulties of the TPACK model. In particular, it was determined that it was difficult to measure the knowledge and beliefs of teachers or pre-service teachers for constructs in the TPACK model (Angeli \& Valanides, 2009; Archambault \& Barnett, 2010; Brantley-Dias \& Ertmer, 2013). In particular, some researchers reported problems in using TPACK measurements due to indefinite definitions and examples of TPACK constructs (Archambault \& Crippen, 2009; Cox, 2008; Cox \& Graham, 2009; Sang et al., 2016).

Several measures developed to draw attention to validity and reliability to assess TPACK constructs between teachers and pre-service teachers (Kopcha, Ottenbreit-Leftwich, Jung \& Baser, 2014, p. 87). However, researcher like Graham (2011) and Abbitt (2011) noted critical issues about the validity and predictability of the TPACK model. According to them, TPACK constructs were not easily identified or separated. However other notable studies showed the construction validity of the TPACK framework (Archambault \& Barnett, 2010; Chai, Ng, Li, Hong, \& Koh, 2013; Drummond \& Sweeney, 2017; Kopcha et al., 2014; Lin, Tsai, Chai, \& Lee, 2013; Schmidt, Baran, Thompson, Mishra, Koehler \& Shin, 2009).

As pointed out by Scherer Tondeur and Siddık (2017), with the efforts to conceptualize these knowledge domains comes the question to what extent they can be distinguished empirically. Kopcha et al (2014) stated that, these related researches suggest that it might be difficult to distinguish between specific TPACK constructs in practice. Although this TPACK framework is interconnected and suggests different sets of knowledge, there is only limited but diverse evidence about the empirical distinction between them (Chai, Koh, \& Tsai, 2010; Chai et al., 2013; Kaya \& Dag, 2013; Koehler, Mishra, Kereluik, Shin, \& Graham, 2014; Koh, Chai, Hong, \& Tsai, 2013; Lee \& Tsai, 2010; Pamuk, Ergun, Çakır, Yilmaz, \& Ayas, 2015; Reyes, Reading, Rizk, Gregory, \& Doyle, 2016; Scherer et al., 2017; Yeh, Hsu, Wu, Hwang, \& Lin, 2017). According to Shin and Mishra (2012), it is important to draw accurate and comprehensive inferences from the TPACK framework. For teacher education and professional development, valid assessments of the TPACK knowledge areas are required.

Due to the fact that the TPACK model is an internal and dynamic construct, it is difficult to measure accurately (Kagan, 1990). In related literature the collection of different types of data (Agyei \& Keengwe, 2014; Angeli \& Valanides, 2009, 2013; Graham, Borup \& Smith, 2012; Hofer \& Grandgenett, 2012; Koehler, Mishra \& Yahya, 2007; Koehler et al., 2012; So \& Kim, 2009) and the use of different methods of data analysis (Drummond \& Sweeney, 2017; Jen, Yeh, Hsu, Wu, \& Chen, 2016; Kopcha et al., 2014; Tondeur, van Braak, Siddiq, \& Scherer, 2014; Yeh, Hsu, Wu, \& Chien, 2014), all should enable for more understanding of the TPACK model and constructs.

This study suggests a new objective measurement of TPACK with different analysis techniques to support the existing TPACK measurements. This study describes the process of determining objective TPACK using Rough Set Analysis. It is expected that this study will be useful in understanding and interpreting the knowledge constructs of the TPACK model in a more accurate and comprehensive sense.

\section{THEORETICAL FRAMEWORK}

\section{Technological Pedagogical Content Knowledge Model}

The concept of TPACK emerged when knowledge on technology was added to the content knowledge of teachers and to their Pedagogical Content Knowledge (PCK), which is a concept 
put forth by Shulman (1986) (Mishra \& Koehler, 2006). TPACK includes Pedagogical Knowledge for the integration of teachers' knowledge and communication technologies (Koh \& Chai, 2016). In principle, TPACK covers three different basic knowledge; Content Knowledge (CK), Pedagogical Knowledge (PK) and Technological Knowledge (TK). TPACK has been put forth from the intersection of these three different fields of knowledge and these three different fields of knowledge have been put forth from the double intersections with TPACK (Mishra \& Koehler, 2006). Teacher knowledge has three main components: content, pedagogy and technology. Interactions between these knowledge constructs are important for the model and at the same time are represented as PCK, TCK (technological content knowledge), TPK (technological pedagogical knowledge) and TPACK (Koehler \& Mishra, 2009).

As described by Mishra and Koehler (2006) TPACK represents the thoughtful interweaving of these "three key sources of information - technology, pedagogy and content". However according to Koehler and Mishra (2009), TPACK is a new knowledge form that goes beyond the three basic components (content, pedagogy and technology). TPACK model is a conception that emerges from the interactions of content, pedagogy, and technology knowledge. Underlying truly meaningful and deeply skilled teaching with technology, TPACK is different from the knowledge of all three concepts individually. TPACK emphasizes the connections and the interactions between content, pedagogy and technology (Mishra \& Koehler, 2006). Koehler et al. (2007) stated that TPACK was a situated form of knowledge required for the intelligent use of technology in teaching and learning. From a different perspective, Brantley-Dias and Ertmer (2013) argue that "TPACK is a complex construct, which has led to a variety of conceptions, definitions, as well as proposed methods for measuring and facilitating its development" (p.121). In several studies, researchers described TPACK characteristics were situated, complex, multifaceted, integrative, and/or transformative knowledge (Angeli \& Valanides, 2009; Harris, Mishra, \& Koehler, 2009; Koehler \& Mishra, 2009; Manfra \& Hammond, 2008).

Moreover, there are scales which were developed for collecting data about TPACK model by Schmith et al. (2009), Graham et al. (2010), Şahin (2011), Chai, Koh and Tsai (2010), Doukakis et al. (2010), Sang et al. (2016), Tondeur et al. (2016), Yeh et al. (2017) and Pamuk et al. (2015). Generally, the purpose of these scales is to determine the TPACK levels of pre-service and inservice teachers. It was determined that for pre-service and in-service teachers' knowledge and perception levels were assessed in TPACK constructs in different disciplines (e.g., mathematics, science and social sciences) by these scales. But there is limited research on interactions and relationships on TPACK model constructs.

In addition to the rising interest and popularity of the TPACK model, there are also various opinions and criticisms related to the limitations of the model. Opinions have been put forth in general regarding the construct of the model and the relationships, interactions and limitations of the constructs within this framework. For example, according to Brantley-Dias and Ertmer (2013), TPACK could be a large (vague or ambiguous) constructs with seven domains of knowledge that would make a reasonable application possible. As stated by Graham et al. (2012), "the TPACK framework adds a significant level of complexity to the already complex PCK framework by more than doubling the number of framework constructs (from three in PCK to seven in TPACK)" (p. 4).

Jimoyannis (2010) suggests that it is not an easy task to reveal the complex network of interaction between content, technology and pedagogy in teaching research. This theoretically creates a need to develop robust TPACK framework. On the other hand, Angeli and Valanides (2009, p. 157), stated that the degree of precision of TPACK should be examined. The degree of precision of a construct refers to the discriminating value of the construct and has important 
implications for its development and assessment. Archambault and Barnett (2010) conducted a study to examine the nature and validity of the TPACK framework. They concluded in their study that the TPACK framework was helpful from an organizational standpoint, however, it was difficult to separate out each one of the components, because measuring each of these components was complicated and convoluted, potentially due to the notion that they were not separate.

While Mishra and Koehler have provided definitions of each construct that articulate to some degree the centers of these constructs (Koehler et al., 2007; Mishra \& Koehler, 2006), the boundaries between them are still quite fuzzy, thus making it difficult to categorize boundary cases (Cox 2008, p. 22). Angeli and Valanides (2009) argue that the conceptualization of TPACK requires theoretical clarity. Their criticism is focused on the current form of TPACK, because of the connections among content, pedagogy, and technology and that appears to be too general.

The boundaries between some components of TPACK, such as what they define as TCK and TPK, are fuzzy; indicating a weakness in accurate knowledge categorization or discrimination; and, a lack of precision in the framework (Angeli \&Valanides, 2009, p.157). As stated by Archambault and Crippen (2009) and Graham (2011), TPACK is built on a "fuzzy" base with domains that lack clear boundaries. Cox (2008) also found that the boundary conditions of TPACK constructs were uncertain. According to Graham (2011), there is very little evidence that her attempt to clarify TPACK construct boundaries have influenced the precision with which other researchers have tried to define their constructs. In addition, Archambault and Barnett (2010) state that the model is experiencing some disappointment with its potential to provide prediction information.

It has been determined that different data analysis techniques have been used in the studies to measure the constructs of the TPACK model (Drummond \& Sweeney, 2017; Jen et al., 2016; Kopcha et al., 2014). Koehler et al. (2014) state that the "high degree of correlation between the subscales of TPACK raises questions about the extent to which the components of TPACK are, in fact, separate components" (p. 106). Chai, Koh, and Tsai (2016) argue that "when the factors are analysed together, construct validity for all seven factors may be problematic" (p. 90). Cox and Graham (2009) argue that the limits of TPACK constructs and the boundaries between these constructs are still fuzzy. Cox and Graham's (2009) TPACK framework provides definitions and distinctions of TPACK constructs, while a clearer definition of TPACK is needed in the context of TPACK. Graham (2011) state that the uncertain boundaries between TPACK knowledge constructs require theoretical development and empirical research. It is said that there is a need for application research is important in different contexts for verification and discussion of TPACK model constructs. It was determined that there was limited research on interaction and relationship of constructs of TPACK model. In this study, a different mathematical analysis approach called rough set analysis is used for providing comprehensive information on interaction and relationship of constructs of TPACK model. This study is aimed to obtain diverse and comprehensive information about TPACK model.

Thus the following questions may arise from TPACK model: does the intersection of TK, CK, PK really make up TPACK? Moreover, what is the relationship between these sets? How can this relationship determined mathematically? The focus of this study has been on such relationships. Similar questions can be asked about the relationships between TK, CK and TCK; PK, CK and PCK; TK, PK and TPK. This research aims to investigate the relationship between TPACK profiles of pre-service mathematics teachers and TPACK constructs with rough set analysis. Because data mining method is used in education technology researches recently (Angeli, Howard, Ma, Yang, \& Kirscher, 2017; Lin, Yeh, Hung, \& Chang, 2013). The use of these analyses in classroom-based 
educational technology research shows that more comprehensive and accurate information can be reached.

It is thought that rough set concept - which enables the mathematical handling of ambiguous concepts in engineering, military, economy, artificial intelligence and education as well as many other fields can be beneficial in this and therefore this study has been designed. It is assumed that a relevant data analysis will be able to explain the relationships in a better way.

\section{Ambiguous Concepts and Rough Set Theory}

The first successful uncertainty approach was the fuzzy sets defined by Zadeh in 1965. In this approach, the membership of an element in a particular set is defined by the membership function. In other words, the expression 'the element is a member of the set at this level' is used in fuzzy sets instead of stating whether the element is certainly a member or not. Another successful uncertainty approach was the rough set concept that was defined by Pawlak in 1982. These sets are used as a mathematical tool to acquire knowledge from uncertain and undefined data (Pawlak, 1991, 1995). It is thought that the rough set theory can be used in the solution of problems such as reduction of data, discovery of dependencies, estimation of the importance of data, setting up of control algorithms from data, the approximate classification of data, the discovery of similarities and differences among the data, the discovery of patterns in the data and, the discovery of causal relations within the data (Aydoğan \& Gencer, 2007; Pawlak \& Slowinski, 1994). There are examples of the theory being applied in different fields as well as in education (Narlı, 2010; Narlı \& Özçelik, 2010; Narlı, Özgen \& Alkan, 2011; Yörek \& Narlı, 2009).

Explanations of TPACK and its related configurations are not sufficiently clear that researchers do not agree on what they are and there are no examples of each constructs (Cox \& Graham, 2009). In study by Graham (2011), he states that limitations is taken into account for TPACK model. Graham (2011) noted that there was still a need to understand the interactions between TPACK's knowledge bases. In his work, he stated that researchers carried out analyses that reveal some understanding of the nature of interactions among knowledge bases. It can be thought that the rough set analysis of the acquired data can be better, as it will enable better comments and will fill the intended gap more fully for information collected from pre-service teachers for TPACK. The emergence of the presented study depends on this assumption.

\section{Purpose of the Study}

In this context, it is thought that the analysis of rough set data would be useful, since there were many complexities and uncertainties in the measurement of TPACK constructs of teachers or/and pre-service teachers. Teachers' focus on cultural/institutional considerations such as classroom logistics and processes, can negatively influence their consideration of TPACK; whereas teachers' beliefs, pedagogical considerations, and the quality of design facilitation positively influence teachers' consideration of TPACK (Koh, Chai, \& Tsai, 2014).

The current issues related to the clarity of TPACK constructs support the need to critically assess the framework and the associated measures (Kopcha et al., 2014). In other words, it is important to clarify that TPACK is not static or fixed, but it is a dynamic and flexible knowledge unit to be affected by rapid changes in technology and bi-directional relationship between knowledge and practice (Cox \& Graham, 2009; Doering, Veletsianos, Scharber, \& Miller, 2009; Mouza, 2009; Mouza, Karchmer-Klein, Nandakumar, Yilmaz Ozden, \& Hu, 2014).

Existing studies in related literature attempted to validate TPACK self-report assessments by investigating their factor structure and the degree to which the knowledge domains can be 
empirically identified (Voogt et al., 2013). Furthermore, it was concluded that the boundaries between the TPACK knowledge domains were often fuzzy (Sang et al., 2016). And, knowledge about these differences extends the existing body of literature and increases our understanding about the nature of TPACK in educational contexts (Scherer et al., 2017). In this context, it can be said that standard measurement and analysis methods are not enough for teacher and preservice teachers to measure complex and uncertain bounded knowledge constructs such as TPACK model.

In this study, it will be examined how CK, TK and PK components measure TPACK level. Besides, it will be tried to explain how the relationships between the knowledge constructs in TPACK model. Rough sets have been used in case of vagueness in fields such as mathematics, computing engineering, as well as philosophy and psychology. It can be argued that this study has shown that rough sets can be used to analyze data in educational research in order to obtain more detailed information about our students' TPACK in certain instances. For the first time in the studies related to TPACK, analysis of the data with the rough cluster data analysis will be done in this study. A different approach was aimed in the analysis of the complex and fuzzy data collected for the TPACK model with the analysis of the rough cluster.

The purpose of this study is to examine pre-service mathematics teachers' TPACK perception using Rough Set Analysis. Furthermore, the aim is to determine this relationship in a manner that will provide mathematical clarity with the help of Rough Set Theory which is used in areas such as artificial intelligence, data reduction, determination of dependencies, estimation of data importance and the establishment of decision (control) algorithms using data. Relationships between Content Knowledge (CK), Pedagogical Knowledge (PK) and Technological Knowledge (TK) with TPACK are also examined by pre-service teachers' perceptions. Results of this study can provide researchers and educators with a better understanding of pre-service mathematics teachers' TPACK components and its relationships.

\section{Research Questions}

Based on the related literature, this study aims to address the following research questions:

- What are the relationships between CK, PK and TK with TPACK?

- How these relationships between CK, PK, TK components and TPACK be determined mathematically using Rough Set Analysis?

- What are the decision rules that have been established between CK, PK and TK with TPACK?

\section{METHOD}

The presented study is a descriptive survey model study. Such studies are carried out to shed light on a given situation, make evaluations according to given standards and put forth the possible relationships between events (Çepni, 2009, p. 64). The objective of the model is to define a completed or ongoing situation. The core of the study where is a situation, an individual or objects are the subject of the study is defined as it is under its own conditions (Karasar, 2008, p. 77). The perceptions of pre-service mathematics teachers about the constructs in the TPACK model have been determined.

\section{Participants}

The study was carried out with a total of 340 pre-service mathematics teachers who were studied at the elementary school mathematics teaching and secondary school mathematics 
teaching programs at a state university in Turkey. The pre-service teachers were randomly selected from the last two year students attending these programs. The reason for students in their final years is the thought that it can contribute to the determination of the perceptions of pre-service mathematics teachers to knowledge types in the TPACK model. In addition, preservice mathematics teachers in these classes had taken various courses on pedagogy and technology. 129 (37.9\%) of the pre-service mathematics teachers who participated in the study were male and 211 (62.1\%) were female. In addition, 213 (62.6\%) of the pre-service mathematics teachers studied their teaching at elementary school mathematics teaching program, whereas $127(37.4 \%)$ studied their teaching at secondary school mathematics teaching program.

\section{Data Collection}

In this study, a scale regarding college students' perceptions in TPACK constructs, which is originally developed by Şahin (2011), was used. In the survey of TPACK, higher scores for each subscale indicate higher perceived acquaintance with the applications of the knowledge base. The TPACK survey included seven subscales (TK, PK, CK, TPK, TCK, PCK, and TPACK) with 47 survey items. The survey items were on a Likert-type scale with five choices for response, including "no knowledge, little knowledge, medium knowledge, quite knowledge and complete knowledge". In the study, the Cronbach alpha reliability coefficient was found to be between 0.83 and 0.90 for the subscales of the survey, which indicated that the instrument was a reliable measure.

\section{Data Analysis}

According to the theory, the subset of a universal set is defined with the help of two sets named as the lower and upper approaches of the subset. Lower and upper approaches are formed by equivalence classes (Pawlak, 1997).

Information table is shown in rough set theory as $T=(U, A, C, D)$. Here, $U$ represents the universal set; $A$ represents the set of properties related to the study area. The $C, D \subset A$ sets specify condition and decision properties respectively.

In case $a \in A$ and $P \subset A$ are taken, the indiscernibility relation $\operatorname{IND}(P)$ pair is defined as:

$$
\operatorname{IND}(P)=\{(x, y) \in U \times U: \forall a \in P \text { for } a(x)=a(y)\}
$$

In case the equality classes set separated by $\operatorname{IND}(P)$ on $U$ is shown by $U / P$, the $U / C$ and $U / D$ sets are named respectively as condition and decision classes. The lower and upper approximate sets of the $X$ set with $R \subset C$ and $X \subset U$ and the boundary region are defined respectively as below:

$$
\begin{gathered}
\underline{R}(X)=\bigcup\{Y \in U / R: Y \in X\}, \bar{R}(X)=\bigcup\{Y \in U / R: Y \cap X \neq \emptyset\}, \\
\operatorname{BN}_{\mathrm{R}}(X)=\bar{R}(X)-\underline{R}(X)
\end{gathered}
$$

According to the Rough Set Theory, $\underline{R}(X)$ set consists of elements that are members of the $X$ set according to the property defined by the $\operatorname{IND}(R)$ equality. Whereas the elements of the $\bar{R}(X)$ set are the probable elements of the $X$ set according to the property defined by the $\operatorname{IND}(R)$ equality. According to the given structure, if the boundary region of the $X$ set is empty, $X$ set is called exact or R-definable set and is called rough set if not. 
Rough sets can be characterized with a constant in the closed interval of $[0,1]$. This constant, which will determine the clarity of the approach is defined as $\alpha_{R}(X)=\frac{|\underline{R}(X)|}{|\bar{R}(X)|}$. It is clear that the $X$ set is exact if $\alpha_{R}(X)=1$ and rough set if not.

Let $C$ and $D$ be condition and decision properties sets respectively. If $k$ is a value calculated as is shown below, it can be said that $D$ is dependent to $C$ at a level of $k(0 \leq k \leq 1)$ and is shown as $C=>{ }_{k} D$.

$$
k=\gamma(C, D)=\frac{\left|P O S_{C}(D)\right|}{|U|}
$$

Here, $P O S_{C}(D)$ is defined as the positive region of $U / D$ quotient according to $C$ and is defined as:

$$
\operatorname{POS}_{C}(D)=\bigcup_{X \in U / D} \underline{P}(X)
$$

In case $k=1, D$ fully depends on $C$. In case $k<1, D$ partially depends on $C$. $\gamma(C, D)$ defines the closeness of the $U / D$ quotient and its estimation according to the conditions at $P$ whereas the $k$ coefficient represents the level of dependency (Pawlak, 1998). With $c \in C$, if $\operatorname{POS}_{(C-(c))}(D)=\operatorname{POS}_{C}(D), c$ is a dispensable property in $T$ information table whereas it is an indispensable property.

Let us assume that $C$ is the set of condition properties in the information table, $D$ is the set of decision properties and $\operatorname{IND}(C)$ is the indiscernibility (equality) relation indicated by the $C$ set. In this case, if $B \subset C$ covers the $\operatorname{IND}(C)$ indiscernibility relation, the properties of $C-B$ may be expended. Subsets that do not include expendable properties are known as reduced property sets. The reduced property set of knowledge TCK is the $B \subseteq C$ smallest property set with

$$
\operatorname{IND}(B)=\operatorname{IND}(C) \text { and } \operatorname{IND}(B-\{a\}) \neq \operatorname{IND}(C)
$$

The intersection of all reduced property sets is known as core. The core may be an empty set. If the set of the reduced property sets of a property set $P$ is shown with $\operatorname{RED}(C), \operatorname{CORE}(C)=\mathrm{n}$ $\operatorname{RED}(C)$.

The significance level of a certain $x \in C$ condition property in $T=(U, A, C, D)$ knowledge TCK is shown as $\sigma_{x}(C, D)$ and this constant is given as $\sigma_{x}(C, D)=[\gamma(C, D)-\gamma(C-\{x\}, D)] /$ $\gamma(C, D)$ (Pawlak, 1997).

Using the Rough Set Method, it has been determined to which group in the sub-groups of the TPACK scale the students belong to. Rough Set Analysis has been used to determine the level of effect TK, PK and CK scores have on TPACK, the level of belonging of pre-service mathematics teachers to other groups who are members of the low, medium or high group in TPACK and the decision rules that can be written between TK, PK and CK and TPACK.

The total scores and averages of pre-service mathematics teachers in the seven sub-scales of TPACK scale were calculated. The pre-service mathematics teachers were included in one of the three groups of low, medium and high according to their average scores in the particular subgroup for Rough Set Analysis. Based on the formula of the interval width, which included dividing the series width by the number of groups to be made (Tekin, 2007), the arithmetical means of the TPACK scale were interpreted as low, medium, and high. Lower and upper limits for these groups were determined as shown in Table 1. 
Table 1. Group Interval Values

\begin{tabular}{cccc}
\hline Group & Low & Medium & High \\
\hline Interval Value & {$[1.0-2.33]$} & {$[2.34-3.67]$} & {$[3.68-5.0]$} \\
\hline
\end{tabular}

Table 2. Condition and Decision Attributes of Data Set

\begin{tabular}{clc}
\hline Label & Attribute & Definition \\
\hline TK & Technological Knowledge & $1-3[\mathrm{~L}(1), \mathrm{M}(2), \mathrm{H}(3)]$ \\
\hline PK & Pedagogical Knowledge & $1-3[\mathrm{~L}(1), \mathrm{M}(2), \mathrm{H}(3)]$ \\
\hline CK & Content Knowledge & $1-3[\mathrm{~L}(1), \mathrm{M}(2), \mathrm{H}(3)]$ \\
\hline TPACK & Technological Pedagogical Content Knowledge & $1-3[\mathrm{~L}(1), \mathrm{M}(2), \mathrm{H}(3)]$ \\
\hline
\end{tabular}

Table 3. Information System for Data Set

\begin{tabular}{ccccc}
\hline & & Condition Attributes & & Decision Attribute \\
\hline Students & TK & PK & CK & TPACK \\
\hline $\mathrm{x}_{55}$ & 1 & 2 & 1 & 1 \\
\hline $\mathrm{x}_{283}$ & 1 & 2 & 1 & 1 \\
\hline $\mathrm{x}_{285}$ & 1 & 2 & 1 & 2 \\
\hline $\mathrm{x}_{44}$ & 2 & 1 & 2 & 1 \\
\hline $\mathrm{x}_{53}$ & 2 & 1 & 2 & 2 \\
\hline $\mathrm{x}_{76}$ & 2 & 1 & 2 & 2 \\
\hline $\mathrm{X}_{4}$ & 2 & 2 & 2 & 1 \\
\hline $\mathrm{x}_{7}$ & 2 & 2 & 2 & 2 \\
\hline $\mathrm{x}_{65}$ & 2 & 2 & 2 & 3 \\
\hline $\mathrm{x}_{134}$ & 3 & 1 & 1 & 2 \\
\hline
\end{tabular}

In order to analyze using rough sets, the three basic types of knowledge (TK, CK, PK) in TPACK model should be in categorical data form. Therefore, the data in these three basic types of knowledge, low, medium and high level area as discussed in the categorical manner. Thus mathematical evidence for the relationship between these knowledge types and determine them together TPACK model was obtained.

\section{RESULTS}

\section{The Effect of TK, PK and CK on TPACK}

A property-value table has been prepared in the Rough Set Analysis process where each row shows an object (or an example) and each column shows a property that defines the object. That is, the condition attributes and decision attributes arrangements of the data have been made. The TK, PK and CK condition attributes have been selected as decision attributes in TPACK (see Table 2).

$T=\{U, A, C, D\}$ knowledge TPACK has been formed for the study using the acquired data. In the table, $U=\left\{x_{1}, x_{2}, \ldots, x_{243}\right\}$ represents the universal set of pre-service mathematics teachers; $A=\{\mathrm{TK}, \mathrm{PK}, \mathrm{CK}, \mathrm{TPACK}\}$ represents the attributes set consisting of technological knowledge, pedagogical knowledge, content knowledge and technological pedagogical content knowledge; $C=\{\mathrm{TK}, \mathrm{PK}, \mathrm{CK}\}$ represents the condition attributes set and $D=\{\mathrm{TPACK}\}$ represents the decision attribute set. The students were labeled according to their scores taken from the applied scale. For instance, the student $x_{55}$ was assigned to "low" group and labeled as " 1 " because his/her mean score for TK subscale was in the interval of [1.0 - 2.33]. Similarly, because his/her mean score for PK subscale was in the interval of [2.34 - 3.67], he/she was assigned to "medium" group and labeled as "2". Similar processes were applied to subscales of CK and TPACK. 10 students example of the knowledge table formed using the acquired data has been given in Table 3. 
In theory, TPACK can be thought of as the cross section of TK, PK and CK. However, when Table 3 is examined; it is observed that students that fall into a low group in TK and CK and those that belong to a medium group in PK can be members of a low group in TPACK as well as taking part in $\left(x_{55}\right.$ and $\left.x_{283}\right)$ a medium group $\left(x_{285}\right)$ as well. Indeed, it can be understood that students that belong to a medium group in TK, PK and CK can be part of low $\left(x_{4}\right)$, medium $\left(x_{7}\right)$ or high $\left(x_{65}\right)$ group in TPACK. As mentioned in the introduction section, there are studies stating that the elementary forms of knowledge (TK, CK and PK) have an indirect effect on TPACK. However, core knowledge basis (PK, CK, TK) had an impact on TPACK development (Pamuk et al., 2015) and they are predictors of teachers' TPACK (Chai et al., 2013; Koh et al., 2014). In this case, can we say that the student $x_{285}$ who is in the medium group in TPACK belongs potentially to a low group? To what extent do TK, PK and CK scores determine TPACK? These questions have been tried to be answered using Rough Set Analysis.

\section{Indiscernibility Relation}

The students have been classified into equivalence classes according to their TK, PK and CK scores using the $R$ equivalence relation; whereas the $U$ universal set has been separated into low $\left(L_{\text {TPACK }}\right)$, medium $\left(M_{\text {TPACK }}\right)$, high $\left(H_{\text {TPACK }}\right)$ sub-sets according to TPACK that determines the decision attribute. The number of members of the sets are respectively $s\left(L_{\mathrm{TPACK}}\right)=58$, $s\left(M_{\mathrm{TPACK}}\right)=220$ and $s\left(H_{\mathrm{TPACK}}\right)=62$. The lower and upper approach sets are important concepts defined by the equality relation of the rough set theory. Lower and upper approach sets have been determined for each of these three sub-sets. Accordingly, the number of elements of the lower and upper approach sets of $L_{\text {TPACK }}$ have been determined as $s\left(\underline{R}\left(L_{\mathrm{TPACK}}\right)\right)=14$ and $s\left(\bar{R}\left(L_{\mathrm{TPACK}}\right)\right)=231$. It is observed that there are 173 elements that belong to the upper approach set but in reality do not belong to the $L_{\text {TPACK }}$ set. Hence, these members are thought to be for students from the lower group in TPACK. 155 of these students belong to the medium group, whereas 18 of them belong to the upper group. However, they are still accepted to potentially belong to the lower group because they are members of the upper approach set $\bar{R}\left(L_{\text {TPACK }}\right)$.

Similarly, the number of elements of the upper and lower approach sets of students that make up the medium group have been determined respectively as $s\left(\underline{R}\left(M_{\mathrm{TPACK}}\right)\right)=22$ and $s\left(\bar{R}\left(M_{\text {TPACK }}\right)\right)=324$. Since the lower approach set consists of 22 members, there are 22 students that absolutely belong to the medium group. In addition, it has been observed when the upper approach set is examined that all students who are not in the medium group but in the high group are potentially medium group students. When a similar analysis is made for upper group students, it was observed that $s\left(\underline{R}\left(H_{T P A C K}\right)\right)=0$ and $s\left(\bar{R}\left(H_{T P A C K}\right)\right)=267$.

Since the boundary sets $B_{R}\left(L_{\mathrm{TPACK}}\right), B_{R}\left(M_{\mathrm{TPACK}}\right), B_{R}\left(H_{\mathrm{TPACK}}\right)$ of the three sets for which upper and lower approaches have been determined above are not empty, these are rough sets. The accuracy level constants of the sets defined in Section 2 have been determined as,

$$
\alpha_{R}\left(L_{\mathrm{TPACK}}\right)=\frac{14}{231} \cong 0.060, \alpha_{R}\left(M_{\mathrm{TPACK}}\right)=\frac{22}{324} \cong 0.067, \alpha_{R}\left(H_{\mathrm{TPACK}}\right)=\frac{0}{267}=0
$$

This shows that the TK, PK and CK scores of students partially explain their TPACK scores.

\section{Dependency of Attributes}

Another important topic of the study was the discovery of the dependencies between attributes. In order to do this, first it was examined to what extent TK, PK and CK determine TPACK. $C=$ 
Table 4. Approximation Qualities

\begin{tabular}{cc}
\hline Attributes & $\gamma$ \\
\hline TK,PK & 0.017 \\
\hline TK,CK & 0.000 \\
\hline PK,CK & 0.002 \\
\hline TK & 0.000 \\
\hline PK & 0.000 \\
\hline CK & 0.000 \\
\hline
\end{tabular}

$\{\mathrm{TK}, \mathrm{PK}, \mathrm{CK}\}$ and $D=\{\mathrm{TPACK}\}$; the extent to which $C$ explains $D$ or in other words the level of dependency of $D$ on $C$ can be given by the equality of:

$$
k=\gamma(C, D)=\frac{\left|P O S_{C}(D)\right|}{|U|}
$$

In our cases this value is as follows.

$$
\gamma(C, D)=\frac{\left|P O S_{C}(D)\right|}{|U|}=\frac{36}{340} \cong 0.105
$$

The obtained result shows to what extent the TK, PK and CK levels of a student explain his/her TPACK level. It is observed that this value is low. In case $k=1, D$ fully depends on $C$ and in case $k<1, D$ partially depends on $C$. From here, it can be calculated to what extent the scores of TK, PK and CK explain TPACK by themselves or in pairs.

Here, if we think that $C=\{\mathrm{TK}, \mathrm{PK}, \mathrm{CK}\}$, the following are obtained: $\operatorname{RED}(C)=\{\{\mathrm{TK}, \mathrm{PK}, \mathrm{CK}\}\}$ and $\operatorname{CORE}(C)=\cap \operatorname{RED}(C)=\{\mathrm{TK}, \mathrm{PK}, \mathrm{CK}\}$. Accordingly, it can be stated that the $C$ set of attributes is irreducible. It is determined that TK, PK and CK sets are inadequate in explaining the TPACK model alone. And, for determining TPACK model, these sets can't be removed.

\section{Significance of Attributes}

The significance levels represented by $\sigma_{x}(C, D)$ in the $T=(U, A, C, D)$ knowledge table for TK, PK and CK each have been determined as $\sigma_{\mathrm{TK}}(C, D)=0.809, \sigma_{\mathrm{PK}}(C, D)=1$ and $\sigma_{\mathrm{CK}}(C, D)=$ 0.838. It is determined that CK, TK and PK are statistically significant predictors of TPACK model. In addition, PK has a strong effect and TK has a lowest significance level on determining TPACK.

\section{Generating Decision Rule Algorithm}

Generating decision is an important topic for knowledge systems. Because, the rules that can be obtained can be used for the determination of the classes that other samples are members of. The generation of rules from knowledge table will be discussed in this section. The relationships between attribute sets and equivalence relations can be used to generate rules.

Let us assume that $Q=\left\{q_{1}, q_{2}, \ldots, q_{n}\right\}$ is an independent set of attributes and that we have a single dependent variable of $d$. Let us represent the equivalence relation of the $Q$ class with $\theta_{Q}$ and that of the $d$ property with $\theta_{d}$. Let us also think that the partition that will be obtained with $\theta_{Q}$ is represented by $\left\{X_{1}, X_{2}, \ldots, X_{s}\right\}$ and that of $\theta_{d}$ is represented by $\left\{Y_{1}, Y_{2}, \ldots, Y_{t}\right\}$. We can associate the $M_{i}=\left\{Y_{J}: X_{i} \cap Y_{J} \neq \emptyset\right\}$ set with each $X_{i}$ set. We can write the following since the $\left\{Y_{1}, Y_{2}, \ldots, Y_{t}\right\}$ set is the partition of the $U$ universal set:

$$
\text { "If } x \in X_{i}, x \in Y_{J}(1) \text { or } x \in Y_{J}(2) \text { or } \ldots x \in Y_{J}(i) \text { " }
$$


Table 5. TPACK Rules

\begin{tabular}{|c|c|c|c|}
\hline Rules & $f$ & $\operatorname{Acc}(r)$ & $\operatorname{Cov}(r)$ \\
\hline IF TK=1, PK=1, CK=1 THEN TPACK=1 & 2 & 1 & 0.034 \\
\hline IF TK=1, PK=1, CK=2 THEN TPACK=1 & 2 & 1 & 0.034 \\
\hline IF TK=1, PK=2, CK=1 THEN TPACK=1 & 2 & 0.666 & 0.034 \\
\hline IF TK=1, PK=2, CK=1 THEN TPACK=2 & 1 & 0.333 & 0.004 \\
\hline IF TK=1, PK=2, CK=2 THEN TPACK=1 & 3 & 0.375 & 0.051 \\
\hline IF TK=1, PK=2, CK=2 THEN TPACK=2 & 5 & 0.625 & 0.022 \\
\hline IF TK=2, PK=1, CK=1 THEN TPACK=1 & 10 & 1 & 0.172 \\
\hline IF TK=2, PK=1, CK=2 THEN TPACK=1 & 5 & 0.50 & 0.086 \\
\hline IF TK=2, PK=1, CK=2 THEN TPACK=2 & 5 & 0.50 & 0.022 \\
\hline IF TK=2, PK=2, CK=1 THEN TPACK=1 & 6 & 0.857 & 0.103 \\
\hline IF TK=2, PK=2, CK=1 THEN TPACK=2 & 1 & 0.142 & 0.004 \\
\hline IF TK=2, PK=2, CK=2 THEN TPACK=1 & 23 & 0.214 & 0.396 \\
\hline IF TK=2, PK=2, CK=2 THEN TPACK=2 & 77 & 0.719 & 0.350 \\
\hline IF TK=2, PK=2, CK=2 THEN TPACK=3 & 7 & 0.065 & 0.112 \\
\hline IF TK=2, PK=2, CK=3 THEN TPACK=2 & 9 & 0.818 & 0.040 \\
\hline IF TK=2, PK=2, CK=3 THEN TPACK=3 & 2 & 0.181 & 0.032 \\
\hline IF TK=2, PK=3, CK=1 THEN TPACK=2 & 1 & 1 & 0.004 \\
\hline IF TK=2, PK=3, CK=2 THEN TPACK $=2$ & 18 & 1 & 0.081 \\
\hline IF TK=2, PK=3, CK=3 THEN TPACK=2 & 8 & 0.571 & 0.036 \\
\hline IF TK=2, PK=3, CK=3 THEN TPACK=3 & 6 & 0.428 & 0.096 \\
\hline IF TK=3, PK=1, CK=1 THEN TPACK=2 & 1 & 1 & 0.004 \\
\hline IF TK=3, PK=1, CK=2 THEN TPACK=2 & 1 & 1 & 0.004 \\
\hline IF TK=3, PK=2, CK=1 THEN TPACK=1 & 2 & 0.400 & 0.034 \\
\hline IF TK=3, PK=2, CK=1 THEN TPACK=2 & 3 & 0.600 & 0.013 \\
\hline IF TK=3, PK=2, CK=2 THEN TPACK=1 & 3 & 0.053 & 0.051 \\
\hline IF TK=3, PK=2, CK=2 THEN TPACK=2 & 43 & 0.767 & 0.195 \\
\hline IF TK=3, PK=2, CK=2 THEN TPACK=3 & 10 & 0.178 & 0.161 \\
\hline IF TK=3, PK=2, CK=3 THEN TPACK=2 & 8 & 0.615 & 0.036 \\
\hline IF TK=3, PK=2, CK=3 THEN TPACK $=3$ & 5 & 0.384 & 0.080 \\
\hline IF TK=3, PK=3, CK=2 THEN TPACK=2 & 15 & 0.555 & 0.068 \\
\hline IF TK=3, PK=3, CK=2 THEN TPACK=3 & 12 & 0.444 & 0.193 \\
\hline IF TK=3, PK=3, CK=3 THEN TPACK=2 & 3 & 0.136 & 0.013 \\
\hline IF TK=3, PK=3, CK=3 THEN TPACK=3 & 19 & 0.863 & 0.306 \\
\hline
\end{tabular}

This relation can be written as below with $f_{q_{1}}(x)$ function representing the value of the $x$ element in the $q_{i}$ property:

$$
\begin{gathered}
\text { "If } f_{q_{1}}(x)=a_{1} \text { and } \ldots \text { and } f_{q_{n}}(x)=a_{n} ; f_{d}(x)=b_{j_{1}} \text { or } \ldots \text { or } f_{d}(x)=b_{j_{i 1}} " \\
A c c(r)=\frac{|\sup (r) \cap D|}{|\sup (r)|}, \operatorname{Cov}(r)=\frac{|\sup (r) \cap D|}{|D|}
\end{gathered}
$$

There are two types of rules in the Rough Set Theory, they are determining and non-determining rules. If the $M_{i}$ set has only a single element, then $X_{i}$ class is called the determining class and the rule that will be generated by this class will be called the determining rule; whereas on the other hand the $X_{i}$ class is called non-determining class, and the rule generated by this class is known as non-determining rule. Different methods can be used in generating decision rules. For example, classification accuracy $\operatorname{Acc}(r)$ the rule coverage $\operatorname{Cov}(r)$ for a certain rule $r$ is defined below. Here, $\sup (r)$ is the number of cases that match the condition part of rule $r$ and $|D|$ is the number of cases that match the decision attributes of the rule.

In the light of the presented concepts, the rules obtained in this study have been given in Table 5. Furthermore, 33 rules have been obtained in the study. 7 of the generated rules are determining, whereas 26 are non-determining. 


\section{DISCUSSION}

In this study, perception of pre-service mathematics teachers regarding the constructs in the TPACK model has been tried to be determined via rough set data analysis. The analysis of acquired data has mathematically put forth that some pre-service mathematics teachers belong to either one of the low, medium and high groups. In terms of TPACK it can potentially be included in other groups as well. On the contrary, it has been determined that there are 36 preservice mathematics teachers that belong to a certain group. It can be stated that the vaguest group is the "high" group. When the certainty values of the low, medium and high group sets are examined, it can be suggested that the borders of the TPACK level set cannot be determined exactly.

In a similar research, Archambault and Crippen (2009) indicated that CK, PK, and PCK items loaded as one factor, whereas TPK, TCK, and TPACK items loaded as another in the result of exploratory factor analysis of a TPACK survey. Moreover, Lee and Tsai (2010) were able to isolate TK, TPK, TCK, and TPACK factors but found that PK and PCK items had loaded as one factor. Drummond and Sweeney (2017) point out that the competence of the teacher in the links between technology, pedagogy and content knowledge (TPACK) is essential for the effective integration of technology into the class. An important question arises from the results of this study and other studies. What are the connections of these knowledge types? In other words, and what is the level of relationships of these knowledge constructs? In this context, Koehler and Mishra (2005) analyzed the conversations between students-teachers and faculty who had to design online courses during a semester. The study indicated that over time the initially separate topics of content, pedagogy, and technology became more strongly interconnected. According to the results of this study, the accuracy of the TPACK levels in the analysis of the knowledge sets of the pre-service teachers was not clear. This result shows that these investigated knowledge constructs do not differ from one another clearly and that there may be different levels and combinations in pre-service teachers.

The analyses of the study have put forth that CK, TK and PK components explain TPACK level at a level of 0.105 but that they fail to explain this level one by one. On the contrary, when one of the components is eliminated from any of the data sets, it is observed that the explanation level decreases to 0.105 . So it is observed that data reduction cannot be carried out in the attribute dataset of CK, TK and PK. This result is in compliance with the technology supported experimental study carried out by Chai et al. (2010) on pre-service teachers regarding the perceptions on the TPACK model constructs before and after the study. It has been determined in the aforementioned study that CK, TK and PK are statistically significant predictors of TPACK and that PK has a strong effect. The rough set data analysis of our study has been able to calculate the significance level of each component and it was observed that the lowest significance level was that of TK (0.809) and that the highest significance level was that of PK (1). Accordingly, it can be stated that the PK component is the most important one in determining the TPACK level. This leads us to think that significant data loss will occur if PK is eliminated from the knowledge TPACK. In addition, relations are concerned with the fact that each of the key factors of TPACK constructs can predict the higher forms of TPACK constructs proposed by Mishra and Koehler (2006).

Another important result of this study is that all CK, TK and PK knowledge constructs are important for TPACK. Furthermore, it has been mathematically determined that one of these data constructs cannot be used for data reduction. And, TPACK model will be adversely affected if one is removed. Pamuk et al. (2015) tested in different ways and came to conclusion that although core knowledge bases (PK, CK, TK) in the model had significant impact on TPACK, their 
predictive powers came through second level knowledge bases (TCK, PCK, TPK). In other words, the direct effects on the TPACK development of core knowledge bases were lower than in the second level knowledge bases. There are various negative opinions regarding the combined use of CK, TK and PK components to explain the TPACK level (Angeli \& Valanides, 2009; Cox, 2008; Graham, 2011). If the study analyses putting forth that these components are able to explain TPACK at a level of 0.105 are considered, some of these criticisms should be taken into account. Since the data is acquired via TPACK scale, the student levels of various relevant components are determined as the levels at which they feel themselves. Hence, the correlation coefficients may be determined to be higher if similar studies are carried out by calculating the CK, TK, PK and TPACK levels of pre-service teachers as they are in reality.

In some studies, results that did not partially match the findings of this study were obtained. In a quantitative study, Koh et al. (2014) found that Singapore teachers did not perceive significant relationships between PCK and TPACK. In addition, Harris et al. (2010) stated that only four of the seven TPACK sizes could be assessed using the course planning evaluation chart. Chai et al. (2013) found that direct positive predictors of TPACK of pre-service teachers were TCK, PCK and TPK, and indirect effects of basic TK, CK and PK.

In this study, the significance levels of TK, CK and PK for TPACK were determined. According to this, it was found that PK was the highest and TK had the lowest significance level. Similar results were determined in past studies. For example, it was found that the TK knowledge construct showed a low level of association with knowledge constructs involving technology (Kaya \& Dag, 2013). Studies focusing on the whole TPACK framework had found moderate to high correlations across all domains (Kaya \& Dag, 2013; Sahin, 2011). In another study, Sang et al. (2016) found that pre-service teachers were able to distinguish overlapping constructs such as TCK, PCK, and TPACK. Scherer et al. (2017) stated that measurement of the technology dimensions in the TPACK framework could capture pre-service teachers' general TPACK beliefs and specific beliefs on technological knowledge. However, given the high correlations between pedagogical dimensions (i.e TCK, TPCK and TPK), the criterion was not able to distinguish four factors (Scherer et al., 2017).

TK, PK and CK constructs in TPACK model are theoretically seen as separate knowledge constructs. However, in this study, it was found that these knowledge constructs were not meaningful alone and that they were meaningful together for the TPACK model. The complexity, interactions and associations of these knowledge constructs present difficulties and uncertainties in measuring them. In the past studies the validity problem was of great importance in the measurement of TPACK constructs.

Studies on the validity of TPACK constructs had determined that lack of clarity of TPACK constructs (Chai, Ng, Li, Hong, \& Koh, 2013; Jang \& Tsai, 2012; Koh, Chai, \& Tsai, 2010; Lin, Tsai, Chai, \& Lee, 2013; Schmidt et al., 2009; Shinas, Yilmaz-Ozden, Mouza, Karchmer-Klein, \& Glutting, 2013). For instance, Drummond and Sweeney (2017) stated that the subjective knowledge assessed by TPACK scales could be supplemented by the inclusion of objective indices of technological pedagogical and content knowledge to form a more complete picture of pre-service teachers' TPACK. Jen et al. (2016) intended to validate features that were typical of levels in a hierarchical structure on the scales of teachers' knowledge about and application of technology for instructional use. Yeh et al. (2014) found that eight knowledge dimensions and 17 indicators of TPACK-practical were validated.

In recent years, studies on TPACK have been an important issue as to how the knowledge constructs can empirically be separated from each other (Scherer et al., 2017). The difficulty of distinguishing between the TPACK constructs also arises when studies are conducted (Kopcha et 
al, 2014). It has been determined that there are some studies that make empirical distinction for TPACK constructs and that there are different measurement and analysis methods (Chai et al., 2010; Chai et al., 2013; Kaya \& Dag, 2013; Koehler et al., 2014; Lee \& Tsai, 2010; Pamuk et al., 2015; Reyes, et al., 2016; Scherer et al., 2017; Yeh et al., 2017). Findings obtained in this study provide important information on the distinction of TPACK constructs by rough set data analysis with different data analysis technique.

Rule generation is an important part of Rough Set data analysis. Rules had been determined in this study. CK, TK and PK levels had been determined using these rules which gave us the opportunity to make comments on the components regarding pre-service teachers. On the other hand, it is also observed that literature mentions generalized rules (Hassanien, 2004). When approached from this perspective, further studies can be carried out to generalize the rules in this study and to obtain simpler rules.

As stated by researchers (Cox \& Graham, 2009; Doering et al., 2009; Mouza, 2009; Mouza et al., 2014), it can be said that TPACK constructs are not fixed or static, but are nonlinear relations. Because it is determined that the rule generation approach in this research can create many rules about the interaction and relation of knowledge constructs of TPACK model. This will provide us with better interpretation and understanding of the TPACK model and the knowledge constructs in the model.

It is observed that the data acquired in this study overlap with the opinions put forth in many other relevant studies. One of the most important criticisms against TPACK model is that the borders of the components are vague in this model and that it is difficult to determine the borders. Angeli and Valanides (2009) stated that the certainty limits of the components in the TPACK model are important. On the other hand, Cox (2008) explained the difficulties of classifying due to the vague borders of the constructs in the model. The accuracy of one of the most important opinions put forth in previous studies regarding the TPACK model has been partially put forth with the application in this study.

As stated by Jimoyannis (2010), the difficulty in putting forth the complex relations between CK, PK and TK as can be seen in this study as well. However, it is understood that theoretical developments are necessary in order to make use of this model more in education applications. It is clear that the certainty levels of the components should be understood in order to make better development and measurements regarding the TPACK model (Angeli \& Valanides, 2009). Hence, applied studies should be carried out for the boundaries and certainty values of the TPACK model as has been done in this study.

Although technology, content, and pedagogy seem to represent different and distinct knowledge bases in this viewpoint, the interactions and connections between these basic concepts form the basis of the overall framework (Archambault \& Barnett, 2010). As discussed by Graham (2011), it was important to identify the basic concepts and relationships between the TPACK components.

Relations between the constructs in the TPACK model have been put forth in a more descriptive manner in previous studies (Graham, 2010). However, it is observed that students need more information in order to make use of this model in their learning processes. It can be stated that the boundaries and certainty values of the TPACK model should be opened to discussion with the data acquired in this study. In addition to the descriptive information on the model, applied work regarding criticisms can be carried out to increase the contribution of the model to the learning process. 


\section{Limitations and Future Research}

In this study, it has been examined to what extent the CK, TK and PK components explain the TPACK level. Other relations in the TPACK model, that is the relationships between TK and CK and TCK as well as the relationship between PK and CK and PCK, and the relationship between TK and PK and TPK, can be examined by future studies. Based on the research findings, it is clear that interactions and relationships among knowledge bases are more complex than as defined or expected. Therefore, we think that although current TPACK schema represents well-defined relationships among knowledge bases and indicates that they all have equal impact on development of TPACK, findings suggest that relationships among TPACK components are poorly-defined and more complex (Pamuk et al., 2015).

Carrying out the study with pre-service mathematics teachers can be seen as a limitation of the study. In future studies, the levels of teachers regarding TPACK or other fields can be determined via Rough Set Analysis. In conclusion, it can be thought that Rough Set Analysis enables us to reach relationships in the TPACK model that other analysis methods cannot determine. It is thought that Rough Set Analysis will be beneficial in other education studies as well.

\section{Conclusions}

In order to explore pre-service mathematics teachers' perceptions about interactions and relationships among knowledge constructs of TPACK. A Rough Set data analysis was conducted for this purpose. This study provides a good example of how educational technologists can use Rough Set Analysis for exploring interactions and relationships among knowledge constructs of the TPACK model. It was determined that the pre-service teachers belonging to any group could potentially belong to other groups in the knowledge constructs of TPACK model. It has been observed that these sets identify rough sets. Furthermore, CK, PK and TK components explain TPACK and that even though the levels of significance of each component are low by itself, it cannot be removed from the data set. Lastly, decision rules have been established between CK, PK and TK with TPACK.

This study will benefit researcher, teachers, teacher educators, and policymakers. Future TPACK research and practical efforts may benefit from the measures of pre-service teachers' knowledge about the intersection and relationships between technology, pedagogy and content. Overall, this research results highlight an important area for the analysis of TPACK scales both teachers and pre-service teachers. Especially, we give concrete example with Rough Set data analysis for the analysis of the TPACK model constructs. Results from this study help establish an empirical basis related to measurement and practices in TPACK development.

\section{NOTE}

This paper was presented at International Conference on Education in Mathematics, Science \& Technology (ICEMST-2016). 


\section{REFERENCES}

Abbitt, J. A. (2011). Measuring technological pedagogical content knowledge in preservice teacher education. Journal of Research on Technology in Education, 43(4), 281-300. https://doi.org/10.1080/15391523.2011.10782573

Agyei, D. D., \& Keengwe, J. (2014). Using technology pedagogical content knowledge development to enhance learning outcomes. Education and Information Technologies, 19(1), 155-171. https://doi.org/10.1007/s10639-012-9204-1

Angeli, C., \& Valanides, N. (2009). Epistemological and methodological issues for the conceptualization, development, and assessment of ICT-TPCK: Advances in technological pedagogical content knowledge (TPCK). Computers \& Education, 52(1), 154-168. https://doi.org/10.1016/j.compedu.2008.07.006

Angeli, C., \& Valanides, N. (2013). Technology mapping: An approach for developing technological pedagogical content knowledge. Journal of Educational Computing Research, 48(2), 199-221. https://doi.org/10.2190/EC.48.2.e

Angeli, C., Howard, S. K., Ma, J., Yang, J., \& Kirscher, P.A. (2017). Data mining in educational technology classroom research: Can it make a contribution? Computers \& Education, 113, 226-242. https://doi.org/10.1016/j.compedu.2017.05.021

Archambault, L. M., \& Barnett, J. H. (2010). Revisiting technological pedagogical content knowledge: Exploring the TPACK framework. Computers \& Education, 55(4), 1656-1662. https://doi.org/10.1016/j.compedu.2010.07.009

Archambault, L., \& Crippen, K. (2009). Examining TPACK among K-12 online distance educators in the United States. Contemporary Issues in Technology and Teacher Education, 9(1). Retrieved from http://www.citejournal.org/vol9/iss1/general/article2.cfm

Aydoğan, E. K., \& Gencer, C. (2007). Veri madenciliği problemlerinde kaba küme yaklaşımı kullanılarak sınıflandırma amaçlı yapıımış olan çalışmalar [The studies conducted using rough set approach for classification of data mining problem]. Kara Harp Okulu Savunma Bilimleri Dergisi, 6(2), 17-32.

Brantley-Dias, L., \& Ertmer, P.A. (2013). Goldilocks and TPACK: Is the Construct "Just Right?". Journal of Research on Technology in Education, 46(2), 103-128. https://doi.org/10.1080/15391523.2013.10782615

Çepni, S. (2009). Araştırma ve proje çalışmalarına giriş [Introduction to research and project work] (3th Edition). Trabzon, Turkey: Celepler Matbaacılık.

Chai, C. S., Koh, J. H. L., \& Tsai, C. C. (2010). Facilitating preservice teachers' development of technological, pedagogical and content knowledge (TPACK). Educational Technology \& Society, 13(4), 63-73.

Chai, C. S., Koh, J. H. L., \& Tsai, C. C. (2013). A review of technological pedagogical content knowledge. Educational Technology \& Society, 16(2), 31-51.

Chai, C. S., Koh, J. H. L., \& Tsai, C. C. (2016). A review of the quantitative measures of technological pedagogical content knowledge (TPACK). In M. C. Herring, M. J. Koehler, \& P. Mishra (Eds.), Handbook of technological pedagogical content knowledge (TPACK) for educators (2 ed, pp. 87-106). New York, London: Taylor \& Francis. 
Chai, C. S., Ng, E.M. W., Li, W. H., Hong, H. Y., \& Koh, J. H. L. (2013). Validating and modeling technological pedagogical content knowledge (TPCK) framework among Asian pre-service teachers. Australasian Journal of Educational Technology, 29(1), 41-53. https://doi.org/10.14742/ajet.174

Cox, S. (2008). A conceptual analysis of technological pedagogical content knowledge (Doctoral dissertation, Brigham Young University, Provo, UT). Retrieved from http://scholarsarchive.byu.edu/cgi/viewcontent.cgi?article=2481\&context=etd

Cox, S., \& Graham, C. R. (2009). Diagramming TPACK in practice: using and elaborated model of the TPACK framework to analyze and depict teacher knowledge. TechTrends, 53(5), 6069. https://doi.org/10.1007/s11528-009-0327-1

Doering, A., Veletsianos, G., Scharber, C., \& Miller, C. (2009). Using the technological, pedagogical, and content knowledge framework to design online learning environments and professional development. Journal of Educational Computing Research, 41(3), 319346. https://doi.org/10.2190/EC.41.3.d

Doukakis, S., Psaltidou, A., Stavraki, A., Adamopoulos, N., Tsiotakis, P., \& Stergou, S. (2010). Measuring the technological pedagogical content knowledge (TPACK) of in-service teachers of computer science who teach algorithms and programming in upper secondary education. In Fernstrom, K. (Eds.), Readings in Technology and Education: Proceedings of International Conference on Information Communication Technologies in Education 2010. Corfu, Greece (pp. 442-452).

Drummond, A., \& Sweeney, T. (2017). Can an objective measure of technological pedagogical content knowledge (TPACK) supplement existing TPACK measures? British Journal of Educational Technology, 48(4), 928-939. https://doi.org/10.1111/bjet.12473

Graham, C. R. (2011). Theoretical considerations for understanding technological pedagogical content knowledge (TPACK). Computers \& Education, 57(3), 1953-1960. https://doi.org/10.1016/j.compedu.2011.04.010

Graham, C. R., Borup, J., \& Smith, N. B. (2012). Using TPACK as a framework to understand teacher candidates' technology integration decisions. Journal of Computer Assisted Learning, 28(6), 530-546. https://doi.org/10.1111/j.1365-2729.2011.00472.x

Graham, C. R., Burgoyne, N., \& Borup, J. (2010). The decision-making processes of preservice teachers as they integrate technology. In D. Gibson \& B. Dodge (Eds.), Proceedings of Society for Information Technology \& Teacher Education International Conference 2010 (Vol. 2010, No. 1, pp. 3826-3832). Chesapeake, VA: Association for the Advancement of Computing in Education (AACE).

Harris, J., Mishra, P., \& Koehler, M. (2009). Teachers' technological pedagogical content knowledge and learning activity types: Curriculum-based technology integration reframed. Journal of Research on Technology in Education, 41(4), 393-416. https://doi.org/10.1080/15391523.2009.10782536

Hassanien, A. E. (2004). Rough set approach for attribute reduction and rule generation: A case of patients with suspected breast cancer. Journal of the American Society for Information Science and Technology, 55(11), 954-962. https://doi.org/10.1002/asi.20042 
Hofer, M., \& Grandgenett, N. (2012). TPACK development in teacher education: A longitudinal study of preservice teachers in a Secondary MA Ed. program. Journal of Research on Technology in Education, 45(1), 83-106. https://doi.org/10.1080/15391523.2012. 10782598

Jen, T.H., Yeh, Y.F., Hsu, Y.S., Wu, H.K., \& Chen, K.M. (2016). Science teachers' TPACK-Practical: Standard-setting using an evidence-based approach. Computers \& Education, 95, 45-62. https://doi.org/10.1016/j.compedu.2015.12.009

Jimoyiannis, I. (2010). Developing a technological pedagogical content knowledge framework for science education: Implications of a teacher trainers' preparation program. In Cohen, E. (Eds.), Proceedings of the 2010 Informing Science \& IT Education Conference (InSITE). Cassino, Italy (pp. 597-607). Informing Science Press. https://doi.org/10.28945/1277

Kagan, D. M. (1990). Ways of evaluating teacher cognition: Inferences concerning the Goldilocks principle. Review of Educational Research, 60(3), 419-469. https://doi.org/10.3102/ 00346543060003419

Karasar, N. (2008). Bilimsel araştırma yöntemi [Scientific research method] (18th Edition). Ankara, Turkey: Nobel.

Kaya, S., \& Dağ, F. (2013). Turkish adaptation of technological pedagogical content knowledge survey for elementary teachers. Educational Sciences: Theory \& Practice, 13(1), 302-306.

Koehler, M. J., \& Mishra, P. (2009). What is technological pedagogical content knowledge? Contemporary Issues in Technology and Teacher Education, 9(1), 60-70.

Koehler, M. J., Mishra, P., \& Yahya, K. (2007). Tracing the development of teacher knowledge in a design seminar: Integrating content, pedagogy and technology. Computers \& Education, 49(3), 740-762. https://doi.org/10.1016/j.compedu.2005.11.012

Koehler, M. J., Shin, T. S., \& Mishra, P. (2012). How do we measure TPACK? Let me count the ways. In R. N. Ronau, C. R. Rakes, \& M. L. Niess (Eds.), Educational technology, teacher knowledge, and classroom impact: A research handbook on frameworks and approaches (pp. 16-31). Hershey, PA: Information Science Reference. https://doi.org/10.4018/978-160960-750-0.ch002

Koehler, M., \& Mishra, P. (2005). What happens when teachers design educational technology? The development of technological pedagogical content knowledge. Journal of Educational Computing Research, 32(2), 131-152. https://doi.org/10.2190/0EW7-01WB-BKHL-QDYV

Koehler, M., Mishra, P., Kereluik, K., Shin, T. S., \& Graham, C. R. 2014. The technological pedagogical content knowledge framework. In Handbook of research on educational communications and technology (pp. 101-111). Springer. Retrieved from http://link.springer.com/chapter/10.1007/978-1-4614-3185-5_9

Koh, J. H. L., \& Chai, C. S. (2016). Seven design frames that teachers use when considering technological pedagogical content knowledge (TPACK). Computers \& Education, 102, 244257. https://doi.org/10.1016/j.compedu.2016.09.003

Koh, J. H. L., Chai, C. S., \& Tay, L. Y. (2014). TPACK-in-Action: Unpacking the contextual influences of teachers' construction of technological pedagogical content knowledge (TPACK). Computers \& Education, 78, 20-29. https://doi.org/10.1016/j.compedu.2014.04.022 
Koh, J. H. L., Chai, C. S., \& Tsai, C. C. (2010). Examining the technological pedagogical content knowledge of pre-service teachers with a large-scale survey. Journal of Computer Assisted Learning, 26(6), 563-573. https://doi.org/10.1111/j.1365-2729.2010.00372.x

Koh, J. H. L., Chai, C. S., \& Tsai, C. C. (2014). Demographic factors, TPACK constructs, and teachers' perceptions of constructivist-oriented TPACK. Educational Technology \& Society, 17(1), 185-196.

Kopcha, T. J., Ottenbreit-Leftwich, A., Jung, J., \& Başer, D. (2014). Examining the TPACK framework through the convergent and discriminant validity of two measures. Computers \& Education, 78, 87-96. https://doi.org/10.1016/j.compedu.2014.05.003

Lee, M. H., \& Tsai, C. C. (2010). Exploring teachers' perceived self-efficacy and technological pedagogical content knowledge with respect to educational use of the World Wide Web. Instructional Science, 38(1), 1-21. https://doi.org/10.1007/s11251-008-9075-4

Lin, C.F., Yeh, Y.C., Hung, Y.H., \& Chang, R.I. (2013). Data mining for providing a personalized learning path in creativity: An application of decision trees. Computers \& Education, 68, 199-210. https://doi.org/10.1016/j.compedu.2013.05.009

Lin, T., Tsai, C., Chai, C. S., \& Lee, M. (2013). Identifying science teachers' perceptions of technological pedagogical and content knowledge (TPACK). Journal of Science and Educational Technology, 22(3), 325-336. https://doi.org/10.1007/s10956-012-9396-6

Manfra, M., \& Hammond, T. C. (2008). Teachers' instructional choices with student-created digital documentaries: Case studies. Journal of Research on Technology in Education, 41(2), 223-245. https://doi.org/10.1080/15391523.2008.10782530

Mishra, P., \& Koehler, M. J. (2006). Technological pedagogical content knowledge: A framework for teacher knowledge. Teacher College Record, 108(6), 1017-1054. https://doi.org/10.1111/j.1467-9620.2006.00684.x

Mouza, C. (2009). Does research-based professional development make a difference? A longitudinal investigation of teacher learning in technology integration. Teachers College Record, 111(5), 1195-1241.

Mouza, C., Karchmer-Klein, R., Nandakumar, R., Yilmaz Özden, S., \& Hu, L. (2014). Investigating the impact of an integrated approach to the development of preservice teachers' technological pedagogical content knowledge (TPACK). Computers \& Education 71, 206221. https://doi.org/10.1016/j.compedu.2013.09.020

Narlı, S. (2010). An alternative evaluation method for likert type attitude scales: Rough set data analysis. Scientific Research and Essays, 5(6), 519-528.

Narlı, S., \& Özcelik, Z. A. (2010). Data mining in topology education: Rough set data analysis. International Journal of the Physical Sciences, 5(9), 1428-1437.

Narlı, S., Özgen, K., \& Alkan, H. (2011). In the context of multiple intelligences theory, intelligent data analysis of learning styles was based on rough set theory. Learning and Individual Differences, 21(5), 613-618. https://doi.org/10.1016/j.lindif.2011.07.012

Pamuk, S., Ergun, M., Çakir, R., Yilmaz, H. B., \& Ayas, C. (2015). Exploring relationships among TPACK components and development of the TPACK instrument. Education and Information Technologies, 20(2), 241-263. https://doi.org/10.1007/s10639-013-9278-4 
Pawlak, Z. (1982). Rough sets. International Journal of Computer and Information Sciences, 11(5), 341-356. https://doi.org/10.1007/BF01001956

Pawlak, Z. (1991). Rough sets-theoretical aspect of reasoning about data. Dordrecht, The Netherlands: Kluwer Academic Publishers.

Pawlak, Z. (1995). Vagueness and uncertainty: A rough set perspective. Computational Intelligence, 11, 277-232. https://doi.org/10.1111/j.1467-8640.1995.tb00029.x

Pawlak, Z. (1997). Sets, fuzzy sets and rough sets. Retrieved on August 01, 2015, from http://bcpw.bg.pw.edu.pl/Content/2026/RoughSetsRep29.pdf

Pawlak, Z., \& Slowinski, R. (1994). Rough set approach to multi-attribute decision analysis. European Journal of Operational Research, 72(3), 443-459. https://doi.org/10.1016/03772217(94)90415-4

Reyes, V. C., Reading, C., Rizk, N., Gregory, S., \& Doyle, H. (2016). An exploratory analysis of TPACK perceptions of pre-service science teachers: A regional Australian perspective. International Journal of Information and Communication Technology Education, 12(4), 114. https://doi.org/10.4018/IJICTE.2016100101

Şahin, i. (2011). Development of survey of technological pedagogical and content knowledge (TPACK). The Turkish Online Journal of Educational Technology, 10(1), 97-105.

Sang, G., Tondeur, J., Chai, C. S., \& Dong, Y. (2016). Validation and profile of Chinese pre-service teachers' technological pedagogical content knowledge scale. Asia-Pacific Journal of Teacher Education, 44(1), 49-65. https://doi.org/10.1080/1359866X.2014.960800

Scherer, R., Tondeur, T., \& Siddiq, F. (2017). On the quest for validity: Testing the factor structure and measurement invariance of the technology-dimensions in the Technological, Pedagogical, and Content Knowledge (TPACK) model. Computers \& Education, 112, 1-17. https://doi.org/10.1016/j.compedu.2017.04.012

Schmidt, D. A., Baran, E., Thompson, A. D., Mishra, P., Koehler, M. J., \& Shin, T. S. (2009). Technological pedagogical content knowledge (TPACK) the development and validation of an assessment instrument for preservice teachers. Journal of Research on Technology in Education, 42(2), 123-149. https://doi.org/10.1080/15391523.2009.10782544

Shinas, V. H., Yilmaz-Özden, S., Mouza, C., Karchmer-Klein, R., \& Glutting, J. J. (2013). Examining domains of technological pedagogical content knowledge using factor analysis. Journal of Research on Technology in Education, 45(4), 339-360. https://doi.org/10.1080/15391523.2013.10782609

Shulman, L. S. (1986). Those who understand: Knowledge growth in teaching. Educational Researcher, 15(2), 4-14. https://doi.org/10.3102/0013189X015002004

So, H. J., \& Kim, B. (2009). Learning about problem-based learning: Student teachers integrating technology, pedagogy, and content knowledge. Australasian Journal of Educational Technology, 25(1), 101-116. https://doi.org/10.14742/ajet.1183

Tekin, H. 2007. Eğitimde ölçme ve değerlendirme [Assessment and evaluation in education] (18th ed.). Ankara, Turkey: Yargı. 
Tondeur, J., Van Braak, J., Siddiq, F., \& Scherer, R. (2016). Time for a new approach to prepare future teachers for educational technology use: Its meaning and measurement. Computers \& Education, 94, 134-150. https://doi.org/10.1016/j.compedu.2015.11.009

Voogt, J., Fisser, P., Pareja Roblin, N., Tondeur, J., \& Van Braak, J. (2013). Technological pedagogical content knowledge (TPACK) - a review of the literature. Journal of Computer Assisted Learning, 29(2), 109-121. https://doi.org/10.1111/j.1365-2729.2012.00487.x

Yeh, Y. F., Hsu, Y. S., Wu, H. K., \& Chien, S. P. (2017). Exploring the structure of TPACK with videoembedded and discipline-focused assessments. Computers \& Education, 104, 49-64. https://doi.org/10.1016/j.compedu.2016.10.006

Yeh, Y. F., Hsu, Y. S., Wu, H. K., Hwang, F. K., \& Lin, T. C. (2014). Developing and validating technological pedagogical content knowledge-practical (TPACK-practical) through the Delphi survey technique. British Journal of Educational Technology, 45(4), 707-722. https://doi.org/10.1111/bjet.12078

Yörek, N., \& Narlı, S. (2009). Modeling of cognitive structure of uncertain scientific concepts using fuzzy-rough sets and intuitionistic fuzzy sets: Example of the life concept. International Journal of Uncertainty, Fuzziness and Knowledge-Based Systems, 17(5), 747769. https://doi.org/10.1142/S0218488509006248

Correspondence: Kemal Özgen, Dicle University, Ziya Gökalp Education Faculty, Mathematics Education, Turkey. E-Mail: ozgenkemal@gmail.com 